\title{
An Agent-Based Approach to Weighted Decision Making in the Spatially and Temporally Variable South African Paleoscape
}

\author{
Colin D. WREN ${ }^{1^{*}}$, Chloe ATWATER ${ }^{2}$, Kim HILL ${ }^{2}$, Marco A. JANSSEN ${ }^{2}$, \\ Jan C. De VYNCK ${ }^{3}$, and Curtis W. MAREAN ${ }^{2,3}$ \\ ${ }^{1}$ Department of Anthropology, University of Colorado - Colorado Springs \\ ${ }^{2}$ School of Human Evolution and Social Change, Arizona State University \\ ${ }^{3}$ Centre for Coastal Paleosciences, Nelson Mandela Metropolitan University \\ corresponding author: cwren@uccs.edu
}

\begin{abstract}
Even a simple human foraging system has a large number of moving parts. Foragers require a complex decision making process to effectively exploit the spatially and temporally variable resources in an environment. Here we present an agent-based modelling framework, based in optimal foraging theory, for agent foragers to make mobility and foraging decisions by weighing expected caloric returns against geographic and social factors, and forecasted future return rates.

We apply our Paleoscape model to a spatially explicit South African coastal landscape to better understand the human foraging system of the Middle Stone Age, when foragers began systematically exploiting a wide variety of flora and fauna in both terrestrial and inter-tidal environments. We also discuss the broader importance of agent-based models of foraging systems for a wide variety of archaeological research questions.
\end{abstract}

Keywords: agent-based modelling, optimal-foraging theory, middle stone age, marine foraging

\section{Project purpose and background}

A basic tenet of the behavioural ecological approach to anthropology is that local ecology, the density and distribution of resources in time and space, determine optimal patterns of economic exploitation of resources. Those optimal foraging, mobility, and grouping patterns then constrain all other aspects of social behaviour, and interact with mating patterns and social norms to produce the core behaviours of society. As such, it is of primary importance that anthropologists develop and test hypotheses about how resource patterning results in basic human economic patterns.

The Paleoscape project was conceived of as a detailed and empirical attempt to reconstruct the hunter-gatherer system during several temporal phases in a coastal South African region. From the outset of the Paleoscape project, we have used optimal-foraging theory (OFT) as a theoretical base with well-established literature to design our agent-based modelling approach (see also Lake, 2000; 2001). The aim is to use this reconstruction to explore a large number of hypotheses related to human behavioural change. Pinnacle Point, Blombos Cave, and Klasies River Mouth are a set of South African coastal archaeological sites and localities well known for behavioural firsts for Homo sapiens; the earliest use of shellfish for food, heat-treatment of stone for lithic manufacture, and ochre for pigment at $162 \mathrm{ka}$ (Marean et al., 2007; Brown et al., 2009), and some of the earliest beads at $72 \mathrm{ka}$ (Henshilwood et al., 2004), among many others. As such, the context for these behavioural changes has come under close scrutiny as they relate to both the behavioural evolution of our species, as well as our expansion out of Africa into the rest of the world relatively shortly after this pivotal period. The context must be conceived broadly to encompass the climate, ecology, and human social behaviour. In previously published articles we have spelled out this broad research project in detail, including the significant progress made so far (Marean et al., 2015; Shook et al., 2015).

The model described in this paper has a rather broad purpose, but is intentionally designed in a rather simple way. This paper will present our reasoning behind the development of this model, its design and current implementation with a particular emphasis on the core mechanism, and an illustration of its potential results. A larger treatment of the empirical data, model runs, and its broader implications for the archaeological record is currently in preparation.

The Agent-Based Model (ABM) described below serves as an endpoint in the collection of a large amount of empirical data collected from specially designed 


\section{Climate States}

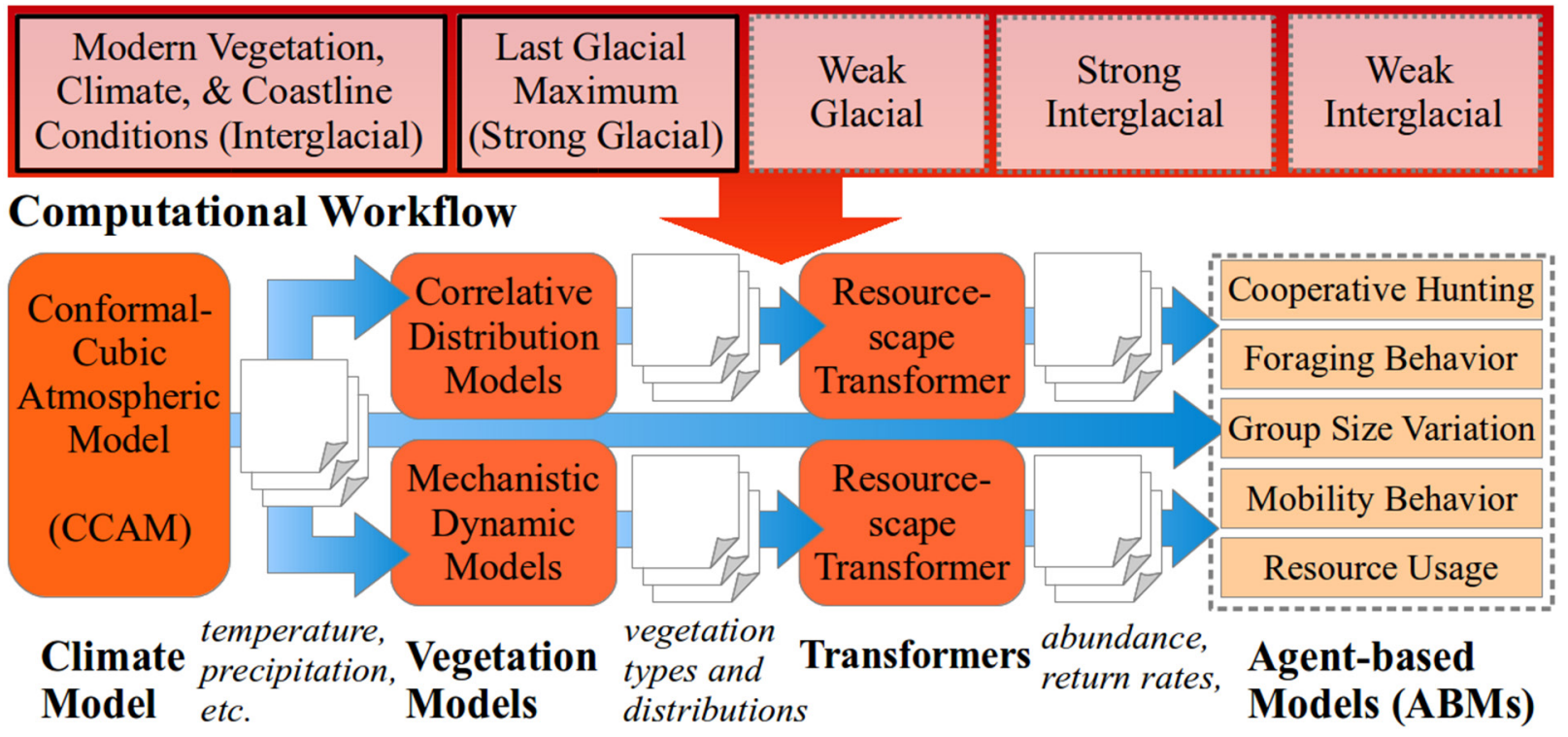

Figure 1. Computational workflow of the Paleoscape Project. Climate, vegetation, and human foraging models are connected using established theory to simulate past human-environment systems during several different temporal phases (reproduced from Shook et al., 2015, Figure 1).

fieldwork and literature reviews (Figure 1). As such, the ABM must be both detailed and flexible enough to accommodate this.

\section{Foraging as base $\mathrm{ABM}$ type}

An additional purpose of this paper is to outline the importance of a key agent based modelling subject for archaeological research; that of a foraging system. A foraging system is the pattern of mobility and collecting decisions hunter-gatherer groups follow to collect the resources they need: food, water, shelter, stone and other materials for making tools, wood for fuel, and even ochre for pigment production. This should not be surprising given the importance of foraging to interpreting behaviour from the archaeological record. However, this commonality has not been explicitly highlighted in archaeological ABMs to our knowledge. We argue here that the foraging $A B M$ is a kind of base ABM type that underlies questions related to huntergatherers' settlement and mobility patterns at the local scale, dispersal at regional and global scale, humanenvironment interactions, behavioural and biological evolution, inter-group interaction, exchange systems, coping with risk from climatic and ecological change, among many others (see Lake, 2014 for a survey of published applications). Since foraging underlies all of these research questions, there should be a systematic focus on the commonalities between the agent-based modelling efforts related to addressing these questions. We will present a beginning to that effort here.
As noted above, OFT is a set of simple models offering a coherent framework for understanding how and why different foraging choices are made within a resource landscape. OFT assumes foragers make choices which maximize a specified fitness-related currency (such as calories) given a known set of available resources, time constraints, costs, and benefits. In these cases OFT models help predict which resources will be collected, how much time should be spent collecting, how many species should be hunted, and so on (Stephens and Krebs, 1986; Winterhalder and Smith, 1981). OFT rigorously defines entities such as habitats, resource patches, and prey items which will be important for our modelling approach. Janssen and Hill (2014) describe in detail the limitations of classic OFT for modelling foraging systems and the advantages of using an ABM approach. For example, the cumulative effects of foraging over long-time scales is better suited to ABM than an algebraic OFT model, as is the effects of intergroup interactions. The ABM framework also allows us to experiment with decision making algorithms designed to reflect different behavioural assumptions and to evaluate their relative effects.

Using OFT as a theoretical base has also helped to guide our empirical data collection efforts by determining what data is needed to reconstruct and evaluate a specific foraging system. Over the past few years, this has led our broader research team to a large number of field and literature surveys into the amount of time required to search, gather, and process resources, travel 

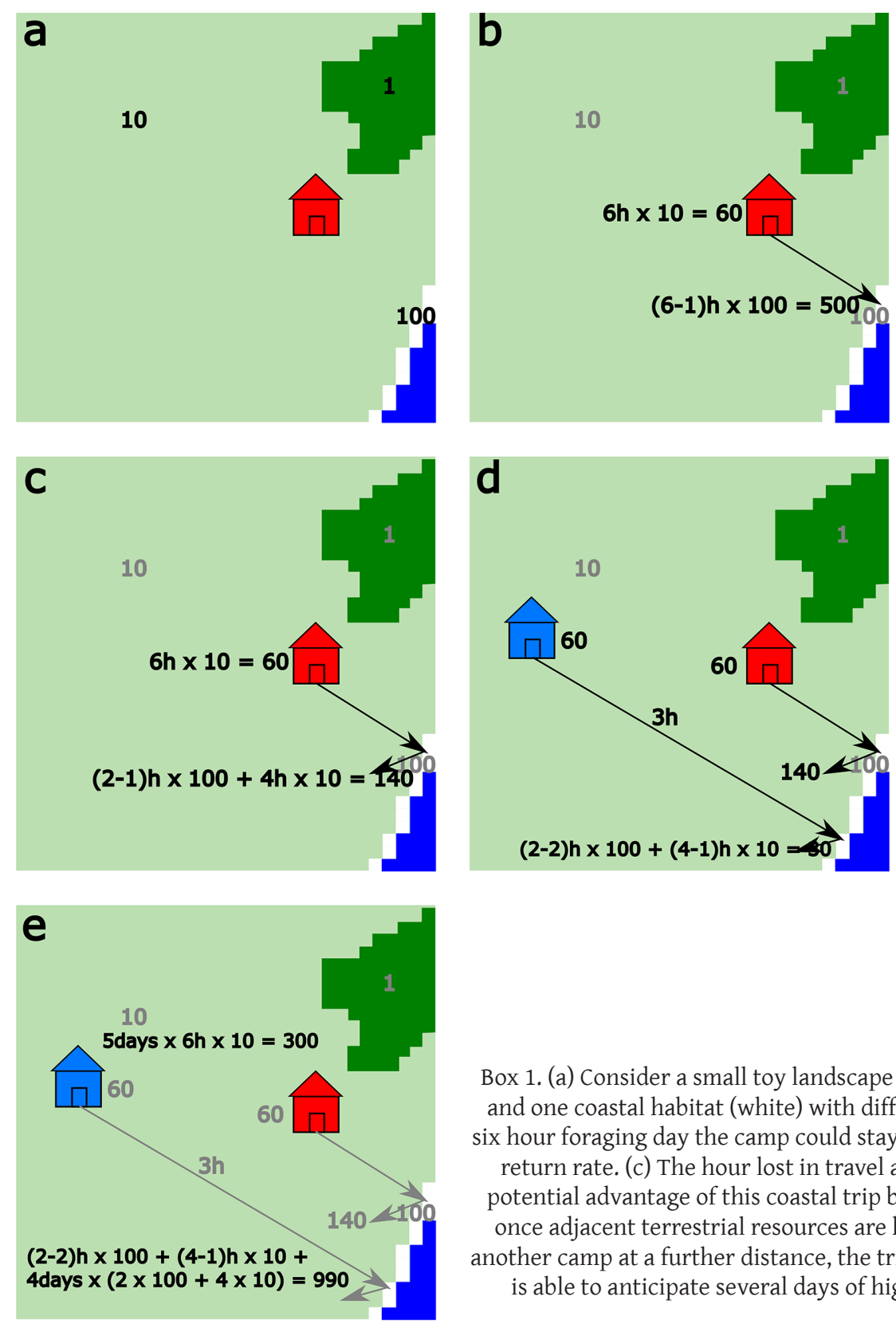

Box 1. (a) Consider a small toy landscape with two terrestrial habitats (green) and one coastal habitat (white) with different return rates in $\mathrm{kcal} / \mathrm{h}$. (b) In a six hour foraging day the camp could stay put or move to the coast for a bigger return rate. (c) The hour lost in travel and the two hour low tide limit the potential advantage of this coastal trip but is still worth the move especially once adjacent terrestrial resources are harvested after the low tide. (d) For another camp at a further distance, the trip is not worth it (e) unless that camp is able to anticipate several days of high returns during the spring tide.

speeds, and the caloric returns of resources in the study region including shellfish (De Vynck et al., 2016a), plants (Singles et al., 2016a;2016b; De Vynck et al., 2016b; 2016c), and terrestrial mammals.

\section{How do you model a forager?}

To blend OFT with the ABM, we base agent decision making on an algorithm designed to make optimal foraging decisions based on maximizing caloric returns within the available daily foraging time (for a similar approach see Lake, 2000, 2001). However, there are a number of complicating factors which are generally relevant to hunter-gather foraging systems, as well as to our agents' decision making in particular. Firstly, resources are spatially variable requiring the agents to account for the net caloric return after travel to a known resource. Secondly, resources are temporally variable requiring agents to not only assess the current resource state, but also to predict when resources will be available before they actually are. This is particularly important given the dramatically different return rates of shellfish based on tide heights driven by lunar cycles (Marean, 2010, 2011, 2014; De Vynck et al., 2016a), but also relates to the seasonal availability of plants, and migratory patterns of some terrestrial mammals. Thirdly, foragers are social and are embedded in systems of cooperation and food sharing within and between groups (Janssen and Hill, 2014, 2016).

\section{Data}

A fuller treatment of the data gathering efforts involved in the Paleoscape project is currently in preparation. 
Here we will simply outline that we have divided up the study region into ecological zones and are undertaking a systematic survey of plant, shellfish, and terrestrial mammal food resources, as well as additional resources such as wood for fuel and raw material for tool making. In each case, through literature reviews and specifically designed in-field experiments with KhoiSan descendants of the region, we have collected data on caloric return rates, and searching and processing times for parameterising the ABM (see table S2 and methodologies in De Vynck et al., 2016a; 2016b; 2016c; Singels et al., 2016a; 2016b). Although the current model uses a pre-agricultural Holocene habitat distribution map as a proxy for the interglacial Middle Stone Age, we are also running simulations of different climate states, and shifting ecological patterns in order to simulate foraging during other temporal phases (Marean et al., 2015; Shook et al., 2015).

\section{The model}

The ABM is programmed using the Netlogo toolkit (Wilensky, 1999), and its basic structure has been adapted from a published model based on the hunting patterns of Ache foragers of Paraguay (Janssen and Hill, 2014; 2016). Like the Ache model, the ABM is made up of three entities, each with their own set of behaviours and variables: cells, camps, and foragers (see SOM for a full model description using the ODD+D protocol). The parameterisation of the model has not been copied from the Ache case study.

The 60,000 cells of the ABM's gridded landscape each represent 1 hectare of habitat with one of 14 defined types. Nine are terrestrial ecological types and an additional four are coastal types. Each type is assigned an average caloric return value in $\mathrm{kcal} /$ hour units based on our empirical research into available food resources. For the purpose of this paper this includes just shellfish for coastal cells and plant resources for terrestrial cells. Terrestrial mammal hunting is being incorporated into a future iteration of the model and the data currently being compiled.

Mobility decisions are made at two temporal scales represented by the camps and the foragers. Camps represent the collective decision making of the foragers and are used for tracking food sharing and average returns of foragers. The camps select and move to a new location at the beginning of each day as a mobility target for the forgers who are members of that camp. The foragers then spend their day making many fine spatial and temporal scale movements to maximize their individual caloric returns.

A large proportion of the model's code and the variables of the three entities are dedicated to the accounting of foraging time spent and left per day, calories acquired and shared, resources available, those left, and the time until they are replenished (see SOM).

A much smaller part of the code is the mechanism through which the foragers and camps make their mobility decisions with the purpose of maximizing net caloric returns. As there are several complicating factors to be accounted for by this mechanism, outlined above, we shall start simply and build up to the full description of the camp's decision making algorithm (see also Box 1).

\section{Spatial variability}

As noted, each cell has a value associated with its return rate (kcal/hour) based on the habitat type. Within a certain perceptual distance, camps assess the different return rates and are able to determine which cells have the largest caloric return for the available hours of foraging time. Since some of these cells are more distant than others, travel time needs to be factored into the mechanism. Often, foraging models will subtract a given amount for the caloric effort required to move (e.g. Lake, 2001). In our model, we focus on a larger factor, which is that the more distant the cell, the more time is spent on travel and thus lost to collecting resources. We therefore subtract the required travel time from the available foraging time in the calculation of net caloric return. Like the marginal value theorem in OFT (Winterhalder and Smith, 1981), the net caloric return after travel to a targeted cell must be greater than the caloric return of the currently occupied cell to justify moving.

\section{Temporal variability}

In a recent paper, De Vynck et al. (2016a) empirically demonstrated Marean's (2010) hypothesis that coastal shellfish are a calorically valuable resource but only if the tides are favourable. The return rate of shellfish varies with two cycles, firstly a daily high-low cycle of $\sim 12$ hours with the highest returns lasting only during the two lowest hours of tide, twice per day. In winter only one low tide is harvestable in daylight, in summer a second low tide might be available during daylight. For simplicity, we assume that shellfish are only harvestable for the first two hours each day, with the rest of the foraging day being spent on nearby terrestrial resources. In a future version of the model, summer's second daily low tide may be included as well.

A second cycle occurs over $\sim 15$ days where full and new moons create additional amplitude of tidal height change known as Spring tides. De Vynck et al. (2016a) demonstrated that high caloric returns are only available around these Spring tides and only for about 
5 days out of every 15 day lunar half-cycle. The ABM cells are updated according to these cycles to reflect the currently available net return rates. Terrestrial plant resources will be similarly updated to reflect seasonal changes when the data has been fully collated (De Vynck et al., 2016b, 2016c; Singels et al., 2016a, 2016b).

\section{Temporal foresight and time discounting}

We noted that travel time is subtracted from available foraging time to arrive at the net caloric return. This could reduce the attractiveness of a high return cell that is at considerable distance. However, the balance of the equation changes if more days of foraging are accounted for. As mentioned, the Spring tide lasts for $\sim 5$ five days (or at least for two hours out of each of five days) and subtracting the travel time needs only to occur on the first of those days. We therefore sum the net caloric return over a given number of days of foresight.

It is advantageous to know when the Spring tide has arrived, but it is even more advantageous to know when it will arrive. This temporal forecasting of a given number of days of foresight has the additional advantage of allowing foragers to arrive as the Spring tide, or other high value resources, becomes available rather than beginning to travel towards it when it arrives and missing the first day or two of high returns. Foragers do not need to be in visual range of the coast to forecast the arrival of the Spring tide. One simple method they may use is to judge by the cycle of lunar phases, another is a more complex calculation involving converting solar days to lunar days. However, the method used is less important than noting that it is possible from far inland.

The final aspect to temporal forecasting to be included is that calories today are comparatively worth more than the same number of calories in the future. This concept, known as time discounting, has been documented in economic contexts (Rogers, 1994) as well as in several ethnographic contexts (Kirby et al., 2002; Rosati et al., 2007; Salali and Migliano, 2015). Several equations exist for calculating the present value of future resources, but the hyperbolic equation (Eq. 1) has been demonstrated to most closely match experimental data (Kirby et al., 2002). The discount rate $k$, that is how steep is the falloff of value with time, varies experimentally, but tends to range between 0.01 and 0.25 . Thus rather than simply summing the resources over several days of foresight, we calculate the present value of future calories according to Eq. 1 before summing them. The primary effect of time discounting in our foraging system is to prevent arriving several days before a resource actually appears (e.g. arriving two days before the Spring tide).

$$
V=\frac{A}{(1+k D)}
$$

where $V$ is the present value of a caloric return $A$ after a delay of $D$ (in days), and $k$ is the discount rate parameter (Kirby et al., 2002).

\section{Decision making algorithm summary}

In summary, the core mechanism of the Paleoscape $A B M$ is a decision making algorithm whereby camps make a prediction about which cell will maximize net caloric returns for its foragers. The algorithm accounts for spatial and temporal variability in resource availability and is able to weigh the spatial and temporal distance against return rates to make the optimal foraging decision for the group. The foragers, since the temporal scale of their decisions is shorter (i.e. fractions of hours) and their spatial range smaller (moving between one hectare cells and perceiving only a small radius around their current location), use a simplified algorithm without temporal foresight and time discounting. The only temporal variability applied by foragers is the above mentioned limitation of only being able to forage for shellfish during the first two hours of their day.

The above series of factors to be incorporated into a decision making algorithm makes what seems like a very simple task, picking the cell with the highest return, much more complicated. However, by basing our approach on OFT and rolling it into one simple core mechanism, our model attempts to avoid many of the pitfalls of an overly complex and un-analysable model.

\section{Runs and model dynamics}

Reporting our analysis of the South African Middle Stone Age foraging system is not the primary purpose of this paper, but a few examples will serve to illustrate the functioning of the model, its decision making algorithm, and its potential for addressing archaeological research questions. It is important to note that the parameterisation of the model (Table S1), and thus all the conclusions below as well, is preliminary as empirical field studies are still underway. Another paper is in preparation that will more fully discuss parameterisation and results of a broader range of model runs.

One of the simplest research questions we have amounts to a detailed account of the carrying capacity. What is the largest viable population size of the South African Cape Floristic Region (CFR) during MIS 5e? This requires not just accounting for consumable resources, but their spatial and temporal distribution, and their sustainability as resources over repeated years of 


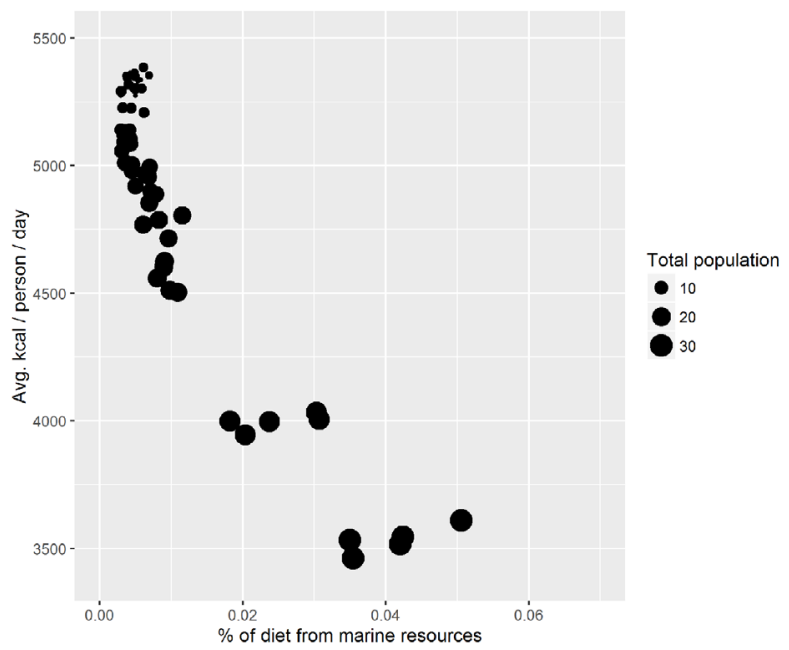

Figure 2. As the population size increases, the average caloric intake of foragers decreases and the proportion of their diet coming from shellfish increases. Foragers are modelled to collect more calories than they personally require (limit set to $5000 \mathrm{kcal} /$ day in these runs) to share with others.

foraging. By conducting runs of the ABM with different population sizes (Figure 2), we can evaluate the longterm viability of different sized populations and the make-up of their diet. To account for stochasticity, we completed five replicate runs of each population size.

It is unsurprising that the average caloric intake of foragers declines with increased population size. However, it is of interest that the proportion of the diet coming from shellfish tends to increase as the population size increases. This suggests that marine resources could be an important fall-back food either when the population is pushing against the limits of the carrying capacity of the plant resource base, as has been suggested during the Late Stone Age (Marean, 2014), or during short-term decreases in plant food availability (not modelled at present). Marean (2015) has argued that marine resources are a dense and predictable resource. We have shown here that they are also more temporally, if not spatially, abundant since they are replenished on each spring tide (every 15 days), whereas once plant resources are depleted from a given patch they won't regrow until the following year.

We then repeated the above runs of population size variation but with the ability to predict when resources will become available over a period of 5 days (particularly shellfish availability based on tidal cycles).

From Figure 3 we can see that increasing temporal foresight has led to an increase in the proportion of the diet coming from shellfish. For the larger population sizes, when plant resources are becoming depleted across the whole landscape, temporal foresight has also

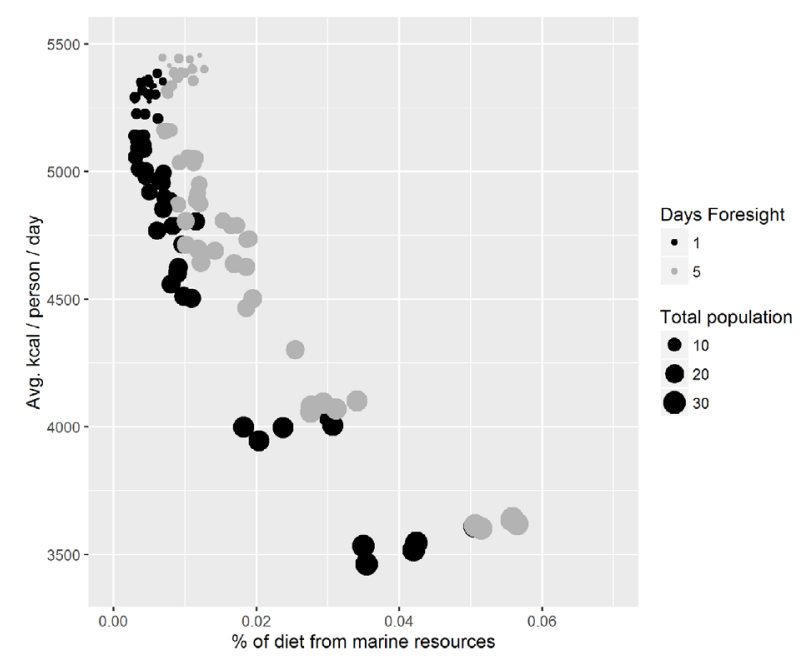

Figure 3. As foragers use temporal foresight to anticipate temporally variable resources like shellfish, they increase the proportion of marine resources in their diet. In these runs, temporal discounting was calculated using $\mathrm{k}=0.1$.

increased the average calorie intake of the population. Beyond just demonstrating that the temporal foresight part of our algorithm works as intended, this may show a tangible caloric benefit of the cognitive capacity previously suggested by Marean (2015).

\section{Discussion}

In this paper we have developed an agent-based model of the foraging system of Middle Stone Age coastal South Africa near the archaeological sites of Pinnacle Point, Blombos Cave, and Klasies River Mouth. The ABM is designed around a decision making algorithm based on optimal foraging theory principles and ethnographic observations. The design allows the model to be both rigorously empirically grounded in a large amount of field data specially collected as inputs to the model, and simple enough to be clearly analysable. The core mechanism of our model is both complex enough to capture the multiple factors involved in optimally selecting sub-hourly foraging decisions within a spatially and temporally heterogeneous resource landscape and flexible enough to be applied to multiple archaeological or ethnographic case studies.

The model outputs have been designed to facilitate comparisons to the published faunal records by allowing comparison between simulated and observed archaeological records of frequency of specific shellfish and mammal species.

We also have emphasised the importance of appropriate theory to ground the bottom-up design of ABMs built to test archaeological research questions. While levels 
of abstraction are required for any modelling (or explanatory) endeavour, some ABMs have not been as rigorously based in theory as they might have been. OFT can provide this basis not just to ABMs with foraging related research questions, but also those focused on the downstream effects of foraging related mobility including: dispersal, population dynamics, inter-group interaction, territoriality, and human-environment interactions. Using this approach has multiple benefits including better comparability among different ABMs, a more systematic basis for the evaluation of model code and results, and comparability to related research in ethnography and ecology.

The decision making algorithm presented here will become more complex as other resources desired by hunter-gatherers are added, such as terrestrial mammal hunting, wood for fuel, raw materials for making tools, fresh water, and ochre for pigment. The present algorithm has established a common currency of calories as a way of making different food resources directly comparable. This approach presents some limitations given some other resources, as well as the physiological requirements for certain proportions of macro-nutrients, are not available in every food resource. Future iterations of the model will address this limitation using established theory from OFT (Hill, 1988).

Although not an initially articulated goal, it is worth noting that the use of this ABM approach within the larger South African Paleoscape research program has led to several new insights and lines of research, as well as novel published work (De Vynck et al., 2016a; 2016b; 2016c; Singels et al., 2016a; 2016b). For example, the combination of an OFT-based approach and ABM development has helped to redesign plant and shellfish sampling protocols. Initially, sampling was focused on the caloric return rates of different resources. However, ABM development has pointed towards the importance of other variables such as walking speed, search times per habitat, and area observed per linear transect.

Rather than being a separate research project, $A B M$ development has been integrated into the broader research goals of the project. In synthesising works, Premo (2010) and Lake $(2010,2014)$ have classified archaeological ABMs by two very distinct goals; hypothesis testing and hypothesis generating (a third was for developing quantitative methods but is not relevant here). Here we have been striving towards both goals, but by using a bottom-up approach based in OFT, we are avoiding problems of circular reasoning. The Paleoscape model can both help to test explicit hypotheses derived from archaeological inference, and help to generate new insights and hypotheses to be addressed using archaeological data by observing unexpected or emergent model dynamics.

\section{Conclusion}

Janssen and Hill $(2014,2016)$ demonstrated that an ABM approach that is carefully grounded in optimal foraging theory can closely replicate ethnographically observed foraging returns of a group of hunters. They also demonstrated that social aspects, like the size of cooperative hunting groups were partly the result of optimizing caloric returns while minimizing risk through food sharing.

In this paper we demonstrate that this approach can also be fruitfully applied to the past where direct ethnographic observation is not possible. Here we describe the decision making algorithm and broad design principles of our model. We present some of the possible model outputs such as the expected proportions of different food resources, effects of changing population size, and the effect of future planning on foraging returns. Future work will greatly expand the range of questions to be explored, including questions related to systems of food sharing, formal tests of hypotheses related to Middle and Late Stone Age foraging behaviour, direct comparisons to archaeological assemblage change over time, and predictions of inter-group interaction, territoriality, and defence.

This formalised framework for investigating past human behavioural hypotheses has been laid out in previously published work (Marean et al., 2015) and after several years of cooperative research, it is paying off. Palaeoclimate models inform paleo-vegetation distribution models which inform the resource-scapes applied to our ABM (Shook et al., 2015). Using this multi-level approach, each grounded in established data, method, and theory we plan to extensively test old hypotheses and generate many new ones. 


\section{APPENDIX}

\section{Model description}

This supplement is a description of our model following the Overview Design Details + Decision (ODD+D) Protocol initially described by Grimm et al. $(2006,2010)$ and later updated by Müller et al. (2012) to incorporate human decision making.

This version of the model is used in Authors (2016) "An Agent-Based Approach to Weighted Decision Making in the Spatially and Temporally Variable South African Palaeoscape" in 44th Computer Applications and Quantitative Methods in Archaeology Conference (CAA2016), Oslo, Norway.

The model is an adapted version of Janssen and Hill's (2014, 2016) model of the hunting system among Ache hunter-gatherers. Like Janssen and Hill, the current model is explicitly based on principles of Optimal Foraging Theory (for an alternative approach to blending OFT and ABM in a foraging model see Lake, 2000, 2001). The principle difference is that the present model is designed for plant and shellfish harvesting rather than hunting. This leads to a cascade of differences in how mobility decisions are made.

\section{Overview}

\section{Purpose}

The purpose of this model is to explore the dynamics of a human foraging system including the exploration of decision making rules for camps and foragers. The landscape and food resources relate to the Middle Stone Age of coastal South Africa during an interglacial phase such as MIS 5e. Several specific research questions will be addressed with the model including maximum sustainable population size, role of inter-tidal foraging in the diet and its impact on mobility patterns, and the impact of future planning. In addition, the process of model development is closely linked to complementary research on the impact of climatic and ecological changes on past human populations.

\section{Entities, state variables, and scales}

There are three types of entities in the model: cells and two types of agents. Cells each represent one hectare of a foraging landscape. A georeferenced raster map of a section of South Africa is imported with values representing one of 14 terrestrial and coastal habitat types. Each cell is assigned associated variables relating to the caloric return rates of harvesting, time required to harvest, current state of depletion, and time until replenishment based on its type. The total landscape is 60,000 hectares, with a fraction of that representing inaccessible ocean.

The return rates of these coastal cells cycle between two values, one for regular and Neap tides which last for 10 days, and one for Spring tides which last 5 days. The spatial and temporal distribution of resource abundance over the landscape influences the pattern of mobility and the proportions of resources collected.

Like the Ache hunting model, there are two types of agents, namely foragers and camps. Camps may move at the beginning of each day but have a limited mobility range. Camps make mobility decisions designed to maximize caloric returns for the group over a given number of days. Foragers are individual people, each a member of specific camp, who have a time budget in hours that are available each day. Foragers make their own mobility and resource harvesting decisions designed to maximize their caloric returns during the time they have left in their day. Foragers' time budgets are reduced by fractions of hours during harvesting and while walking between cells. Camp and forager variables are used to keep track of time left and kilocalories collected.

\section{Process overview and scheduling}

Each time step represents one day. At the beginning of the day, cells and camps are updated. A 15 day tidal cycle advances by one day and if in the last 5 days of this, return rates are updated to reflect Spring tide resource availability even if it had been harvested during the previous 10 days. Depleted terrestrial cells decrease their time until regrowth by one day and if at zero, their return rate is replenished. The camps then use a decision making algorithm to decide on their location for the end of the day. The maximum range of this move is $75 \%$ of a day's walk from their previous location but may be a much shorter distance. If the selected cell is within range they will move to it, if it is beyond their range they will move as far as they can in the direction of that cell.

Foragers then begin a loop where they make mobility and harvesting decisions with the time they have left in their day. During each iteration of the loop, foragers in random order estimate the time required to walk directly to their assigned camp. If their time left is greater, they make a mobility decision designed to maximize their daily caloric return. After moving to a 
cell, they subtract their travel time. They harvest 20\% of the resources of that cell, reflecting a linear $100 \mathrm{~m}$ transect with $10 \mathrm{~m}$ visible on either side, and subtract the time expended in harvesting that resource. We assume that foragers are able to observe a previous forager's transect and thus, the return rate of each cell remains constant until it is completely depleted (Figure $\mathrm{S} 1)$. If their travel time to camp is less than or equal to their time left, they move one cell towards their camp and do not harvest resources. Foragers repeat this loop until they run out of foraging time. As harvest times are different per habitat, foragers are asynchronous during each day. When all foragers have used up their time and returned to camp average caloric returns are calculated by each camp.

Upon being fully harvested, terrestrial cells set a counter to 365 days. This counter is decreased each day to simulate plant regrowth and as cells reach zero, their resources are replenished. More detailed plant surveys are underway in South Africa and additional details regarding seasonal plant cycles or differing regrowth rates will be incorporated into a future model.

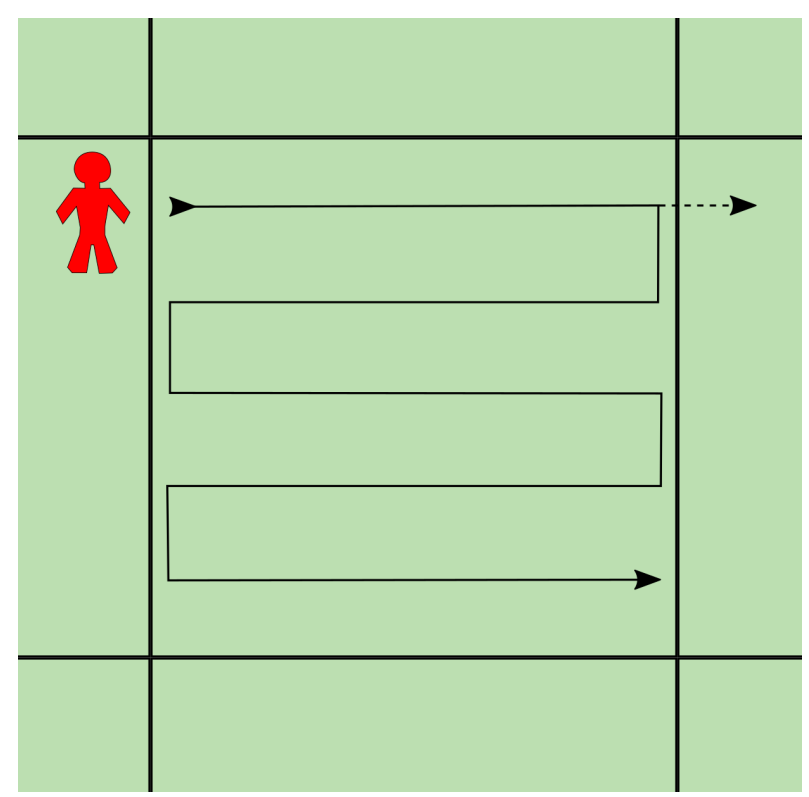

Figure S1. Schematic of a forager agent systematically searching a single cell (solid arrow). By not overlapping the swaths (we assume they are able to recognize previous foragers' harvesting activities) they maintain a constant return rate over five passes across the cell. Alternatively,

the forager could decide after the first pass that the neighbouring cell has a higher return rate and move there

(dashed arrow). That would leave the cell with the same return rate but $20 \%$ less harvestable time available to future foragers.

\section{Design concepts}

\section{Theoretical and empirical background}

The model design is based on Optimal Foraging Theory (OFT) and implemented according to OFT's definitions of habitats, patches, and prey (Stephens and Krebs, 1986; Janssen and Hill, 2014, 2016). Habitats are geographical regions with consistent characteristics such that a statistically constant pattern of food resources will be encountered. This leads to an average expected return rate for individuals searching that habitat. Patches are smaller units of habitat with a finite number of resources. On the time scale relevant to daily foraging, patches may be depleted as their return rate relative to other patches drops. In our model we assume a systematic search per patch, which means that the return rate per patch remains constant until that cell's resources have been completely exhausted at which point no other resources are available. While our field research has shown that certain plant resources do appear in concentrated clumps only a few meters across, at the scale of a hectare an individual forager has a reasonably consistent return rate given a habitat specific amount of searching and processing time. In the current implementation, there are no prey species.

While the broad framework of the model is based on OFT and ethnographic observations, some model details have been incorporated that are specific to South Africa. For example, water availability has not been included as a constraint on camp location decisions. A paper on this subject is in preparation, but preliminary data suggests that water sources are relatively well distributed across the landscape and therefore would not have been as important a constraint in most habitats as in some other regions (Cowling and Mars, personal communications). We have worked closely with a variety of researchers with knowledge of South African archaeology, ethnography, ecology, botany, and marine biology to ensure the relevant factors are being considered in the decision making framework of camps and foragers.

\section{Individual decision making}

Camps and foragers make similar decisions designed to maximize their caloric return given their available time. In each case, the agent assesses individual patches with the assumption that its neighbouring patches will be similar. That is, the return rate of a cell is multiplied by up to several days of foraging time even though that patch may be fully exploited in a fraction of that time. This is a reasonable, though not strictly accurate, heuristic that we use for computational efficiency. This heuristic introduces some uncertainty into the estimated return for camps and foragers since the neighboring cells may not have the same return rate or 
may be depleted. We assume that camps and foragers have prior experience in this landscape and thus know the condition of cells in the landscape. No partial memory aspect is included. See below for details.

\section{Learning}

Camps and foragers do not learn or adapt their decision making strategies in this version of the model.

\section{Individual sensing}

In their decision making algorithm, camps use the daily foraging budget, distances to assessed cells, return rate of all cells, and whether a cell is depleted or not. In assessing the return rate, camps also understand the impact of the tidal cycles on return rates, and may forecast the high return Spring tides several days in advance. Although not explicitly modeled, camps are assumed to have global knowledge of current return rates through information exchange and experience.

Foragers keep track of how much time they have left in their day, the distance to their camp and how much time it will take to travel there, how many kilocalories they have collected so far that day, and the current return rate of patches within a specified radius and coastal patches even if they are outside of the radius.

\section{Individual prediction}

Although not explicitly modeled, camps and foragers are assumed to have knowledge of the tidally affected coastal return rates through the observation of lunar phases. This also allows camps to anticipate the arrival of the Spring tide. A future version of the model will incorporate data from seasonal plant phenology for predicting the availability of plant resources as well.

\section{Interaction}

Camp and forager interaction is indirect as their mobility decisions are affected by other foragers' depletion of resources. However, the location of other foragers and camps are not factored into mobility decisions.

\section{Collectives}

Camps consist of a number of foragers who begin their day at the previous day's camp location, and end their day at the new camp site. Average caloric returns are calculated both for individual foragers as well as for camps under an assumption of food sharing. Foragers are assigned a camp on initialization of the model and do not change camps.

\section{Heterogeneity (agents)}

Agents are not heterogeneous in their state variables or processes. All agents use the same decision algorithm.

\section{Stochasticity}

The order in which camps move, and foragers move and forage, is randomized. Since each forager is indirectly affected by the distribution of available resources, there is a minimal impact of this randomization. In certain rare circumstances, a forager is not able to move to or towards the cell they determine to have the highest net return due to an uninhabitable cell being in the way (such as an ocean). In these cases, foragers move to a randomly selected cell in their immediate 8-cell neighbourhood to help them continue moving.

\section{Observation}

Output variables will vary based on the specific research question being evaluated. The model accounts for time spent and calories collected per forager, per camp, and per cell. These may then be aggregated into average caloric returns, days without food, and ratios of different food types (e.g. plant vs marine, or per habitat type). Mobility characteristics such as frequency of camp movement, distance traveled per camp or forager, and time spent in proximity to the coast may also be measured.

\section{Details}

\section{Implementation details}

The model is implemented in Netlogo 5.3.1 and may be downloaded from the author's CoMSES.net account $^{1}$ (Wren, 2016).

\section{Initialization}

During the setup procedure, variable settings are read from the user interface to determine which landscape will be used, and how many camps and foragers there will be. Setup assigns return rates and harvesting times to all cells based on their habitat type. Several other accounting variables are set to zero such as calories collected and distance traveled. Additionally, if a number of days of foresight are being used, a temporal multiplier is calculated using the hyperbolic timediscounting formula. All terrestrial cells are set to be full of resources which results in the first year of the simulation being more productive than subsequent years. 


\section{Input data}

\section{Habitat data}

The habitat map consists of two data sources. Vector GIS layers of terrestrial habitats were taken from a digital appendix to Mucina and Rutherford (2006) and converted into raster format at one hectare resolution. This pre-agricultural Holocene distribution is used as a proxy for the interglacial Middle Stone Age. Climate and vegetation simulations are underway to model habitats for other climate phases.

The coastline of the study region were walked in order to sample underlying geology. De Vynck et al. (2016a) found that shellfish return rates varied consistently with underlying geology and used this as the basis for differentiating returns rates among other variables. We used GPS data from this coastline survey and combined it with the terrestrial data to create a raster model of all habitats at 1 hectare resolution divided into 14 distinct habitat types.

Details of field experiments in coastal shellfish foraging are documented in De Vynck et al. (2016a), and in plant foraging in De Vynck et al. (2016b, 2016c) with some additional caloric data from Singels et al. (2016a, $2016 b)$. Note that the values in the table are estimated given currently available data, but that more rigorous estimates are underway.

\section{Parameter values}

Other parameter values are either estimated from ethnographic sources or are actively being derived from fieldwork in South Africa. For example, walking speeds through different habitats are being recorded during the process of plant surveying. The amount of harvesting time available to foragers is estimated from ethnographic sources including Hill's work with Ache foragers of Paraguay (Janssen and Hill, 2014, 2016) and this is consistent with Hadza foragers in nearby Tanzania (Hawkes et al., 1997). One exception to these two sources is the camp mobility distance which is calculated as a percentage of a day's walk (Eq. S3).

\section{Submodels}

Here we discuss the details of the forager and camp mobility decisions, the tidal cycle, and including our implementation of forecasting return rates over several days.

\section{Camp decision algorithm}

Camps assess all cells then select the cell which has the maximum net caloric return determined by Eq. S1. If the cell is a coastal cell, an adjustment is made as the return rate is different for the two hours of lowest tide at the beginning of the day versus the remaining hours. In this case, the first two hours (minus travel time) are multiplied by the low tide return rate, followed by the remaining hours multiplied by a randomly selected adjacent terrestrial cell (which are generally higher than the high tide return rate).

Available time may also be multiplied over a specified number of days of foresight to reflect future planning. In these cases, the caloric returns of future days are discounted according to a hyperbolic time discounting

\begin{tabular}{|c|l|l|l|}
\hline Habitat ID & Habitat Name & $\begin{array}{l}\text { Return rate } \\
\text { (kcal/hr) }\end{array}$ & $\begin{array}{l}\text { Harvest time } \\
\text { (hours/ha) }\end{array}$ \\
\hline 1 & Freshwater wetlands & 2000 & 17.9 \\
\hline 2 & Alluvial vegetation & 1160 & 13.4 \\
\hline 3 & Strandveld & 1200 & 1.17 \\
\hline 4 & Saline vegetation & 0 & 0.83 \\
\hline 5 & Renosterveld & 100 & 0.67 \\
\hline 6 & Sand Fynbos & 1020 & 0.72 \\
\hline 8 & Albany Thicket & 100 & 0.65 \\
\hline 9 & Limestone Fynbos & 470 & 0.70 \\
\hline 10 & Aeolianite & $1450(\mathrm{l}) / 250(\mathrm{~h})$ & 1.5 \\
\hline 11 & Sandy beach & $150(\mathrm{l}) / 250(\mathrm{~h})$ & 1.5 \\
\hline 12 & TMS Boulders & $1100(\mathrm{l}) / 250(\mathrm{~h})$ & 1.5 \\
\hline 13 & TMS Rocky Headlands & $1100(\mathrm{l}) / 250(\mathrm{~h})$ & 1.5 \\
\hline 14 & TMS Wave Cut Platforms & $1100(\mathrm{l}) / 250(\mathrm{~h})$ & 1.5 \\
\hline & & & \\
\hline
\end{tabular}

Table S1. Return rates and harvest times per habitat type. Habitat IDs 10 or more are coastal habitats which have different return rates for the lowest (l) two hours of tide vs. the rest of the day (h). 


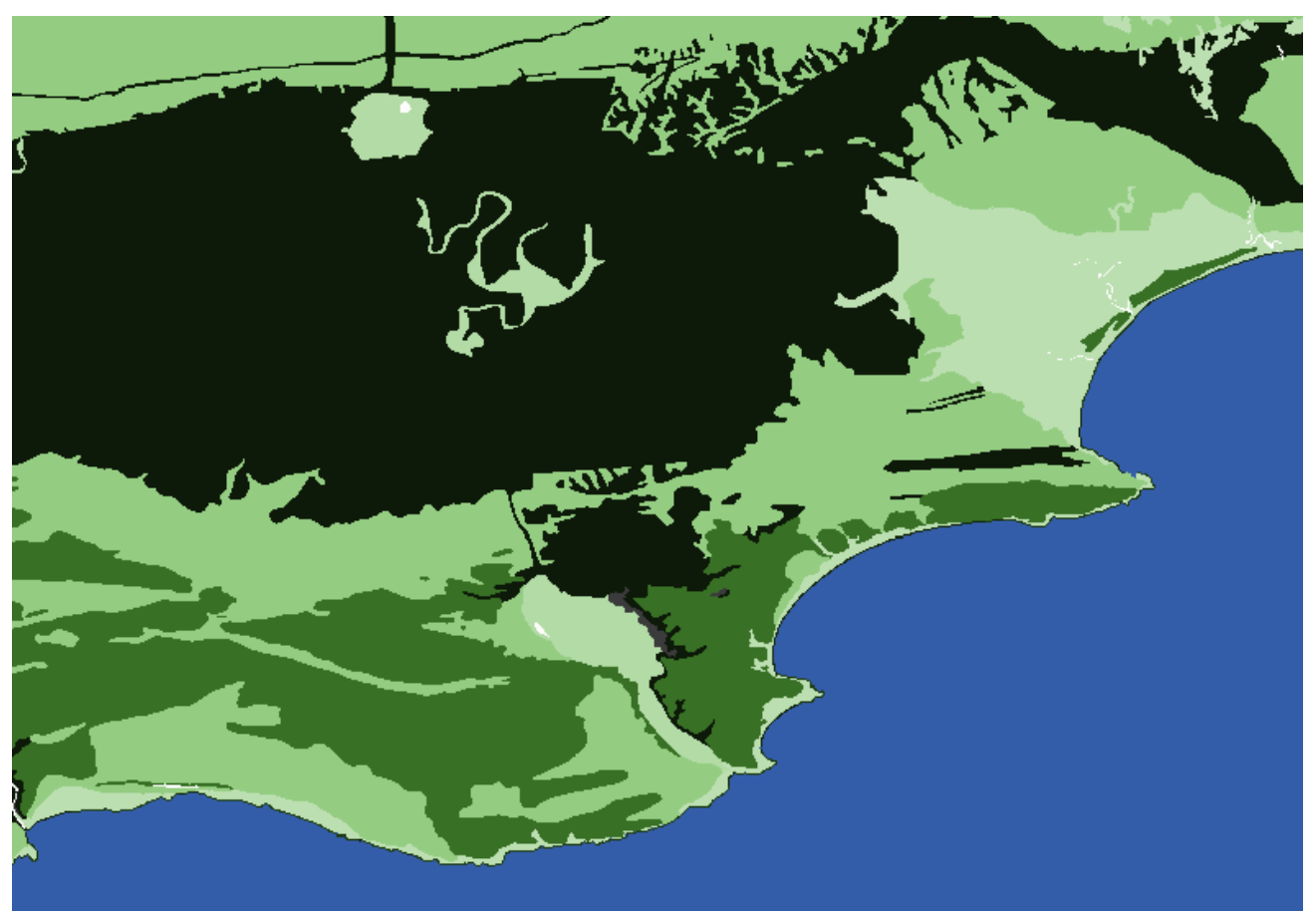

Figure S2. Screenshot of the Netlogo raster landscape where habitats are colour scaled according to their caloric return rates (lighter shades = higher returns). This view is during a neap tide when coastal returns rates are low (black).

\begin{tabular}{|c|c|c|c|}
\hline Parameter & Description & Default value & Value range \\
\hline nragents & Number of foragers per camp & 7 & $1-30$ \\
\hline nrcamps & Number of camps & 3 & $1-30$ \\
\hline Walk-speed (km/hr) & $\begin{array}{l}\text { Speed foragers will walk when } \\
\text { not harvesting resources }\end{array}$ & 2 & $1-5$ \\
\hline Camp-mobility & $\begin{array}{l}\text { Maximum distance a camp } \\
\text { may travel per day }\end{array}$ & Eq. S3 & $\mathrm{n} / \mathrm{a}$ \\
\hline Vision-forager (cells) & $\begin{array}{l}\text { Distance in hectare cells that } \\
\text { a forager sees when making a } \\
\text { mobility choice }\end{array}$ & 10 & $5-75$ \\
\hline Vision-camp (cells) & $\begin{array}{l}\text { Distance in cells that a camp } \\
\text { sees when making a mobility } \\
\text { choice (if global-knowledge } \\
\text { is off) }\end{array}$ & 50 & $1-50$ \\
\hline Global-knowledge? & $\begin{array}{l}\text { Switch to determine if camps } \\
\text { have knowledge of all cells, or } \\
\text { only ones within the vision- } \\
\text { camp radius }\end{array}$ & True & True/False \\
\hline Map-zone & $\begin{array}{l}\text { Selects the full region or } \\
\text { different sub-zones of the } \\
\text { study area }\end{array}$ & z2 (Pinnacle Point) & z1 (Vleesbaai), z2, or full \\
\hline Max-kcal-collect (kcal) & $\begin{array}{l}\text { Maximum number of } \\
\text { resources a forager will collect } \\
\text { in a day }\end{array}$ & 5000 & $1000-5000$ \\
\hline Days-of-foresight & $\begin{array}{l}\text { Number of days camps will } \\
\text { forecast return rates over }\end{array}$ & 1 & $1-5$ \\
\hline Discount-rate & $\begin{array}{l}\mathrm{k} \text { in Eq. S2. Controls the } \\
\text { steepness of the fall-off in } \\
\text { value with days of foresight }\end{array}$ & 0.1 & $0.01,0.1,0.25$ \\
\hline
\end{tabular}

Table S2. Default values and ranges for other parameters used in the model. 
formula (Eq. S2). The discount rate parameter $(k)$ determines the fall-off rate of value with number of days in the future.

$$
\begin{aligned}
& \text { Net caloric return }=((\text { discounted_return }) * \\
& \text { hours_per_day }-(\text { distance } / \text { camp_mobility } * \\
& \text { hours_per_day } * \text { current_return_rate })
\end{aligned}
$$

where camp_mobility is defined by Eq. S3 and discounted return represents the summed returns over a defined number of days of foresight $\left(\mathrm{d}_{\mathrm{f}}\right)$

$$
\text { discounted_return }=\sum_{D=0}^{d_{f}} \frac{A}{(1+k D)}
$$

where $A$ is the caloric return after a delay of $D$ (in days), and $k$ is the discount rate parameter and

camp_moblility $=$ daily_time_budget $*$ walk_speed $* 10 * 0.75$

which assumes that the maximum distance the camp can move in one day is $75 \%$ of a day's constant walking.

\section{Forager decision algorithm}

Like camps, foragers assess cells (within a visual range) and select the cell with the maximum net caloric return (Eq. S4). The algorithm similarly subtracts travel time and adjusts for the low and high tides. The only difference is that foragers' available time is based on how much time they have left in their day and no future days are accounted for.

$$
\begin{aligned}
& \text { Net_caloric_return }=(\text { current_return_rate } * \text { time_left })- \\
& \text { (distance } * \text { time_walk_cell) }
\end{aligned}
$$

where time_walk_cell is the time in hours needed to walk $100 \mathrm{~m}$ as calculated from the walk_speed.

\section{Lunar tidal cycle and forecasting}

The 15 day lunar cycle has a dramatic effect on the return rates of inter-tidal shellfish availability such that only around the spring tides, are foragers able to get a sufficiently high caloric return to justify the risk of acquiring the resource. De Vynck et al. (2016a) demonstrated that under the best combination of conditions return rates could exceed $3000 \mathrm{kcal} / \mathrm{hr}$. However, waves along this coastline can be powerful and could sweep foragers off slippery rocks into the ocean making the lower return rates during nonSpring tides much less attractive. Our intertidal foraging experiments during different parts of the lunar cycle and under a variety of weather and forager characteristics have led us to determine that only 5 days out of each 15 day cycle have high return rates, with the other 10 being much lower.
A tidal-cycle procedure updates the return rates of coastal cells at the beginning of each model day. If a coastal cell is fully depleted during a non-Spring day, it will be replenished to the full return rate on the first Spring tide day to reflect foraging lower in the intertidal zone. If a cell is fully depleted during a Spring tide day, that cell will not be replenished until the beginning of the next Spring tide (i.e. will remain at zero return rate during the 10 days of non-Spring tides). Although this replenishment rate may seem surprising, our fieldwork has demonstrated that inter-tidal return rates are sustainable at this rate (De Vynck, personal communication).

To allow for forecasting return rates over a number of days of foresight, a list of return rates over the 15 day cycle is first established based on whether or not the cell is currently depleted. The position in the list is determined by where on the tidal cycle the current day rests, and then a sublist of based on the number of days of foresight under consideration is extracted. The discounted return formula (eq. S1) is then applied but using the different return rates for Spring tides and non-Spring tides instead of a fixed return rate.

\section{References}

Brown, K.S., Marean, C.W., Herries, A.I., Jacobs, Z., Tribolo, C., Braun, D., Roberts, D.L., Meyer, M.C., and Bernatchez, J. (2009) 'Fire as an engineering tool of early modern humans', Science 325 (5942), pp. 859862. doi: 10.1126/science.1175028.

De Vynck, J.C., Anderson, R., Atwater, C., Cowling, R.M., Fisher, E.C., Marean, C.W., Walker, R.S., and Hill, K. (2016a) 'Return rates from intertidal foraging from Blombos Cave to Pinnacle Point: understanding early human economies', Journal of Human Evolution, 92 (March), pp. 101-115. doi: 10.1016/j. jhevol.2016.01.008.

De Vynck,J.C., Cowling, R.M., Potts, A.J., and Marean, C.W. (2016b) 'Seasonal availability of edible underground and aboveground carbohydrate resources to human foragers on the Cape south coast, South Africa', PeerJ, 4:e1679. doi: 10.7717/peerj.1679.

De Vynck, J.C., Van Wyk, B.-E., and Cowling, R.M. (2016c) 'Indigenous edible plant use by contemporary Khoe-San descendants of South Africa's Cape South Coast', South African Journal of Botany, 102 (January), pp. 60-69. doi: 10.1016/j.sajb.2015.09.002.

Grimm, V., Berger, U., Bastiansen, F., Eliassen, S., Ginot, V., Giske, J., Goss-Custard, J., Grand, T., Heinz, S.K., Huse, G., Huth, A., Jepsen, J.U., Jørgensen, C., Mooij, W.M., Müller, B., Pe'er, G., Piou, C., Railsback, S.F., Robbins, A.M., Robbins, M.M., Rossmanith, E., Rüger, N., Strand, E., Souissi, S., Stillman, R.A., Vabø, R., Visser, U., and DeAngelis, D.L. (2006) 'A standard 
protocol for describing individual-based and agentbased models', Ecological Modelling, 198 (1-2), pp. 115-126. doi: 10.1016/j.ecolmodel.2006.04.023.

Grimm, V., Berger, U., DeAngelis, D.L., Polhill, J.G., Giske, J., and Railsback, S.F. (2010) 'The ODD protocol: a review and first update', Ecological Modelling, 221 (23), pp. 2760-2768. doi:10.1016/j.ecolmodel.2010.08.019.

Hawkes, K., O'Connell, J.F., and Blurton Jones, N.G. (1997) 'Hadza women's time allocation, offspring provisioning, and the evolution of long postmenopausal life spans', Current Anthropology, 38 (4), pp. 551-577.

Henshilwood, C., d'Errico, F., Vanhaeren, M., van Niekerk, K., and Jacobs, Z. (2004) 'Middle Stone Age shell beads from South Africa', Science, 304 (5669), p. 404. doi: 10.1126/science.1095905.

Hill, K. (1988) 'Macronutrient modifications of optimal foraging theory: an approach using indifference curves applied to some modern foragers', Human Ecology, 16 (2), pp.157-197. doi: 10.1007/BF00888091.

Janssen, M.A. and Hill, K. (2014) 'Benefits of grouping and cooperative hunting among Ache huntergatherers: insights from an agent-based foraging model', Human Ecology, 42 (6), pp. 823-835. doi: 10.1007/s10745-014-9693-1.

Janssen, M.A. and Hill, K. (2016) 'An agent-based model of resource distribution on hunter-gatherer foraging strategies: clumped habitats favor lower mobility, but result in higher foraging returns', in Barceló, J.A. and Del Castillo, F. (eds) Simulating prehistoric and ancient worlds. Basel: Springer International Publishing, pp. 159-174. Series: Computational Social Sciences. doi: 10.1007/978-3-319-31481-5_3.

Kirby, K.N., Godoy, R., Reyes-García, V., Byron, E., Apaza, L., Leonard, W., Pérez, E., Vadez, V., and Wilkie, D. (2002) 'Correlates of delay-discount rates: evidence from Tsimane' Amerindians of the Bolivian rain forest', Journal of Economic Psychology, 23 (3), pp. 291316. doi: 10.1016/S0167-4870(02)00078-8.

Lake, M.W. (2000) 'MAGICAL computer simulation of Mesolithic foraging', in Kohler, T.A. and Gumerman, G.J. (eds) Dynamics in human and primate societies. Agent-based modeling of social and spatial processes. New York: Oxford University Press, pp. 107-143. Series: Santa Fe Institute Studies in the Sciences of Complexity.

Lake, M.W. (2001) 'The use of pedestrian modelling in archaeology, with an example from the study of cultural learning', Environment and Planning B: Planning and Design, 28 (3), pp. 385-403. doi: 10.1068/ b2726.

Lake, M.W. (2010) 'The uncertain future of simulating the past', in Costopoulos, A. and Lake, M.W. (eds) Simulating change: archaeology into the twenty-first century. Salt Lake City: University of Utah Press, pp. 12-20.
Lake, M.W. (2014) 'Trends in archaeological simulation', Journal of Archaeological Method and Theory, 21 (2), pp. 258-287. doi: 10.1007/s10816-013-9188-1.

Marean, C.W. (2010) 'Pinnacle Point Cave 13B (Western Cape Province, South Africa) in context: The Cape Floral kingdom, shellfish, and modern human origins', Journal of Human Evolution, 59 (3-4), pp. 425443. doi: $10.1016 / j$.jhevol.2010.07.011.

Marean, C.W. (2011) 'Coastal South Africa and the coevolution of the modern human lineage and the coastal adaptation', in Bicho, N., Haws, J.A., and Davis, L.G. (eds) Trekking the shore. Changing coastlines and the antiquity of coastal settlement. New York: Springer, pp. 421-440. Series: International Contributions to Archaeology. doi: 10.1007/978-14419-8219-3_18.

Marean, C.W. (2014) 'The origins and significance of coastal resource use in Africa and Western Eurasia', Journal of Human Evolution, 77 (December), pp. 17-40. doi: 10.1016/j.jhevol.2014.02.025.

Marean, C.W. (2015) 'An Evolutionary anthropological perspective on modern human origins', Annual Review of Anthropology, 44 (October), pp. 533-556. doi: 10.1146/annurev-anthro-102313-025954.

Marean, C.W., Anderson, R.J., Bar-Matthews, M., Braun, K., Cawthra, H.C., Cowling, R.M., Engelbrecht, F., Esler, K.J., Fisher, E., Franklin, J., Hill, K., Janssen, M., Potts, A.J., and Zahn, R. (2015) 'A new research strategy for integrating studies of paleoclimate, paleoenvironment, and paleoanthropology', Evolutionary Anthropology: Issues, News, and Reviews, 24 (2), pp. 62-72. doi: 10.1002/evan.21443.

Marean, C.W., Bar-Matthews, M., Bernatchez, J., Fisher, E., Goldberg, P., Herries, A.I.R., Jacobs, Z., Jerardino, A., Karkanas, P., Minichillo, T., Nilssen, P.J., Thompson, E., Watts, I., and Williams, H.M. (2007) 'Early human use of marine resources and pigment in South Africa during the Middle Pleistocene', Nature, 449 (7164), pp. 905-908. doi: 10.1038/ nature06204.

Mucina, L. and Rutherford, M.C. (eds) (2006) The vegetation of South Africa, Lesoto and Swaziland. Pretoria: South African National Biodiversity Institute. Series: Strelitzia 19.

Müller, B., Bohn, F., Dreßler, G., Groeneveld, J., Klassert, C., Martin, R., Schlüter, M., Schulze, J., Weise, H., and Schwarz, N. (2013) 'Describing human decisions in agent-based models-ODD + D, an extension of the ODD protocol', Environmental Modelling \& Software, 48 (October), pp. 37-48. doi: 10.1016/j. envsoft.2013.06.003.

Premo, L.S. (2010) 'Equifinality and explanation: the role of agent-based modeling in postpositivist archaeology', in Costopoulos, A. and Lake, M.W. (eds) Simulating change: archaeology into the twentyfirst century. Salt Lake City: University of Utah Press, 
pp. 28-37. Series: Foundations of Archaeological Inquiry.

Rogers, A.R. (1994) 'Evolution of time preference by natural selection', The American Economic Review, 84 (3), pp. 460-481.

Rosati, A.G., Stevens, J.R., Hare, B., and Hauser, M.D. (2007) 'The evolutionary origins of human patience: temporal preferences in chimpanzees, bonobos, and human adults', Current Biology, 17 (19), pp. 16631668. doi: 10.1016/j.cub.2007.08.033.

Salali, G.D. and Migliano, A.B. (2015) ‘Future discounting in Congo Basin hunter-gatherers declines with socio-economic transitions', PLOS ONE, 10 (9), e0137806. doi: 10.1371/journal.pone.0137806.

Shook, E., Wren, C., Marean, C.W., Potts, A.J., Franklin, J., Engelbrecht, F., O’Neal, D., Janssen, M., Fisher, E., Hill, K., Esler, K.J., Cowling, R.M., Scheiter, S., and Moncrieff, G. (2015) 'Paleoscape model of coastal South Africa during modern human origins: progress in scaling and coupling climate, vegetation, and agent-based models on XSEDE', in Proceedings of the XSEDE15 Conference: Scientific Advancements Enabled by Enhanced Cyberinfrastructure. New York: ACM. doi: 10.1145/2792745.2792747.

Singels, E., Esler, K.J., Cowling, R.M., Potts, A.J., and De Vynck, J. (2016a) 'The role of geophytes in stone-age hunter-gatherer diets', Quaternary International, 404 (Part B), pp. 210-211. doi:10.1016/j. quaint.2015.08.208.

Singels, E., Potts, A.J., Cowling, R.M., Marean, C.W., De Vynck, J., and Esler, K.J. (2016b) 'Foraging potential of underground storage organ plants in the southern Cape, South Africa', Journal of Human Evolution, 101 (December), pp. 79-89. doi: 10.1016/j. jhevol.2016.09.008.

Stephens, D.W. and Krebs, J.R. (1986) Foraging theory. Princeton: Princeton University Press.

Winterhalder, B. and Smith, E.A. (eds) (1981) Huntergatherer foraging strategies: ethnographic and archeological analyses. Chicago: University of Chicago Press. Series: Prehistoric Archaeology and Ecology.

Wilensky, U. (1999) NetLogo Home Page [Version: NetLogo 6.0.4]. Evanston IL: Center for Connected Learning and Computor-Based Modeling, Northwestern University. Available at: htpp://ccl.northwestern. edu/netlogo/ (Accessed: 24 April 2018).

Wren, C. (2016) An agent-based approach to weighted decision making in the spatially and temporally variable South African Paleoscape [Version 1.0.0]. CoMSES Computational Model Library. Available at: https:// doi.org/10.25937/r2qq-fn02 (Accessed: 16 July 2018). 
